\title{
Relational geography of a border island: local development and compensatory destruction on Lieyu, Taiwan
}

\author{
Su-Hsin Lee \\ National Taiwan Normal University, Taiwan \\ shlee@ntnu.edu.tw \\ Wen-Hua Huang \\ National Taiwan Normal University, Taiwan \\ ecohook@gmail.com
}

and

\author{
Adam Grydehøj \\ Island Dynamics, Denmark \\ Institute of Island Studies, University of Prince Edward Island, Canada \\ agrydehoj@islanddynamics.org
}

\begin{abstract}
The paper considers Lieyu island from a relational geography perspective, relative to the islands of Kinmen, Xiamen, and Taiwan. Lieyu retains its natural landscape and military heritage in part due to its remote location and military restrictions relative to nearby Kinmen Island. Local politicians harness Lieyu's archipelagic relationality and sense of underdevelopment relative to other islands in its archipelago to gain financial subsidies for infrastructure development. Such infrastructure projects (including fixed links) endanger Lieyu's sense of islandness and island place. We introduce the term 'compensatory destruction', which involves destroying existing place-based values or attributes in the process of implementing new values in the name of development. Although compensatory destruction is not necessarily bad, care must be taken to ensure that development projects serve the needs of the community as a whole and are adequately assessed and evaluated.
\end{abstract}

Keywords: compensatory destruction, islands, Kinmen, local development, relational geography, Taiwan, Xiamen

https://doi.org/10.24043/isj.33

(C) 2017 — Institute of Island Studies, University of Prince Edward Island, Canada.

\section{Introduction}

This paper analyses how archipelagic relationality affects place identity and infrastructural development on Lieyu, a small island in Taiwan's Kinmen Archipelago. We argue that Lieyu's political, economic, and social relationships at different island scales (with the large adjacent Kinmen Island, with the main island of Taiwan, and with the nearby mainland Chinese island city of Xiamen) produce a sense of underdevelopment and spur efforts to overcome relative inequality. This results in processes of compensatory destruction, in which existing place-based values are replaced in the pursuit of development. 
Development studies on small islands have traditionally focused on developmental strategies and economic growth, with an emphasis on the state perspective and economic aid (Selwyn, 2011; Clark, 2009). In recent years, however, the orientation of development studies has diversified (Haynes, 2008; Nederveen Pieterse, 2010; Willis, 2011), though geography-oriented development studies remain an exception. Willis and Kumar (2009) recommend that geographyoriented development studies gain greater awareness of space and scale, especially the flow of capital, population, and ideas as well as the exercise of power at various scales. With the increasing importance attached to island studies, scholars from geography and other disciplines have directed focus toward island development (Beller et al., 1990; Royle, 2001; Baldacchino, 2007). This research, however, comes with risks: Clark (2013) warns against standardised, proscriptive models of development, while Grydehøj $(2017$, p. 9) highlights how development-oriented island research often fails to allow "islanders themselves to set the agenda."

It is important to consider the 'relational governance' of large and small islands (Baldacchino \& Tsai, 2014). Island-mainland relationships played an important role in early island studies thinking, which emphasised territorial boundaries and borders yet was less attentive to islanders and local perspectives (Royle, 2001; Vannini \& Taggart, 2012). There has developed a desire within island studies to rethink inter-island movements and relationships beyond static island/mainland binaries (Stratford et al., 2011; Pugh, 2013, 2016; Rankin, 2016). The field has undergone a 'relational turn', in line with the growing popularity of relational approaches in the broader post-structural geography and other disciplines. Massey (1993), for example, suggests that places are constructed through rootedness and roundedness, through their connections with various other places around the world; places are not defined by clear borders or a singular sense of place identity. Place is inherently relational inasmuch as it is linked to power, exclusion, and difference (Cresswell, 2013). The 'relational turn' thus suggests that places are not necessarily conservative and passive but can also be extroverted and politically active. This developing island studies theorisation is important given that islands have longed played a major role in discourse, thinking, and traditions around the world (Gillis, 2004; Hay, 2006), though there has been a lack of research taking a non-Western perspective on the meaning of islandness (Luo \& Grydehøj, 2017). The present paper is thus useful in part because it considers archipelagic relationality from an East Asian perspective, examining relationships between politically distinct islands, states, and countries.

This study is grounded in long-term ethnographic research (July 2013-February 2017) into how islanders establish their model of island culture and maintain social order. The main research methods are participant observation (mainly of public hearings, local activities, local community websites, local media reports, and conversations on ferries) and interviews (with a total of 41 subjects, including members of the general public, village/township leaders, cultural and historical workers, educators, media journalists, tourists, and local public servants). Interviewees have been anonymised and numbered. The interviews included questions concerning opinions on Lieyu's development, dependence on other places, uniqueness, and recent changes on Lieyu. Because social construction of place is usually rooted in empirical facts as perceived by residents, such construction further triggers the unravelling of place meanings. Local social construction is deeply embedded in Lieyu residents' traditions.

\section{Lieyu within an archipelagic system}

Lieyu is an offshore island of Taiwan. It is located less than $2 \mathrm{~km}$ west of Kinmen Island (the main island in the Kinmen Archipelago) and is northeast of the very small islands of Dadan and Erdan. Xiamen, an island of mainland China, is itself located just $5 \mathrm{~km}$ to the west of Lieyu, yet Lieyu and Xiamen are not only very different in size and population but also embedded in very different cultural, political, and economic systems. The main island of Taiwan is located $228 \mathrm{~km}$ to the east of Lieyu. This paper considers Lieyu's inter-island relationships within this complex, multiscalar archipelagic system. This approach follows the example set by Baldacchino and Tsai (2014), who analyse Taiwan's archipelagic 'metageographies'. 

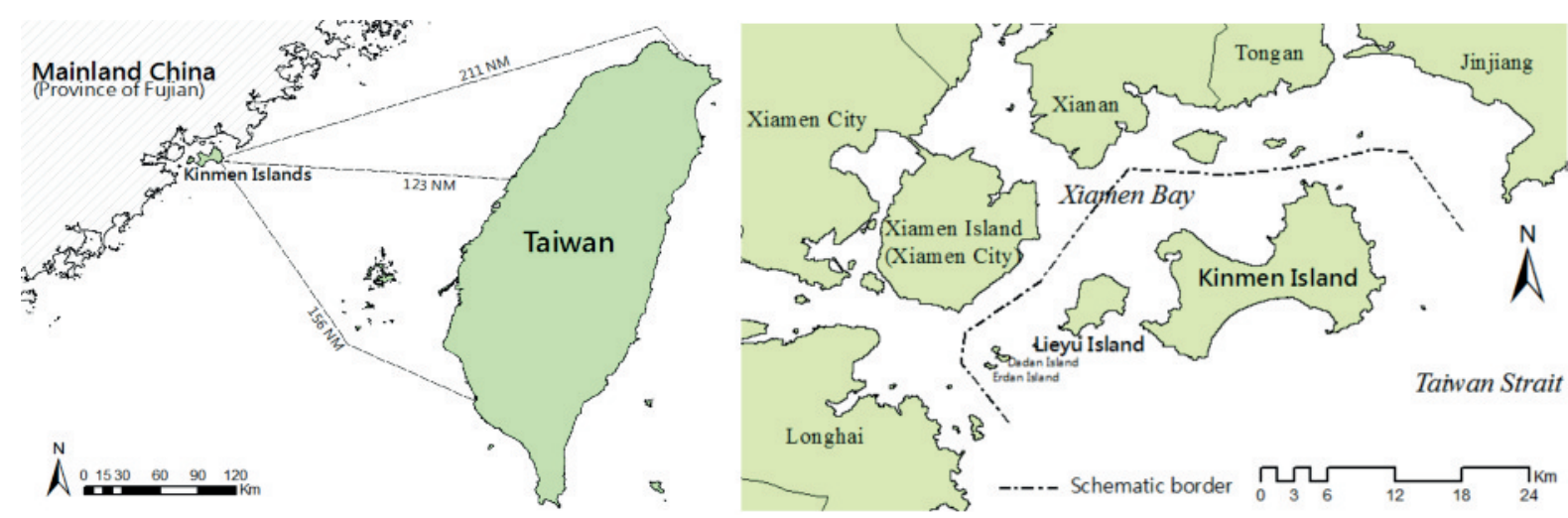

Figure 1: The location of the Kinmen archipelago (left) and the relative location of Lieyu within Xiamen Bay. (C) Wen-Hua Huang)

Xiamen — with its population of around 1,900,000; its land area of around $158 \mathrm{~km}^{2}$; its status as a major centre of industry, financial services, and trade; and its fixed transport links (bridge, causeway, and tunnel) with the mainland - is evidence that not all islands are marginalised and remote. Indeed, Xiamen is part of a historical tendency for small, near-shore islands to develop into major economic centres and ultimately spread out to and physically connect with the mainland, both in China and farther afield (Grydehøj, 2015; Sheng et al., 2017; Steyn, 2015). Islands may, however, face extreme developmental challenges if they are located at the periphery, far from decision-making centres; possess limited natural resources and skill foundations; have small internal markets and fluctuating income; and are subject to high transportation costs (Figueroa \& Rotarou, 2016).

For most of the 20th century, Lieyu possessed a marginal economy (Xu J.T., 2016). Following the Chinese civil war, which ended in 1950, the Kinmen archipelago remained under the control of the Kuomintang government that had retreated to Taiwan. Like the Matsu archipelago to the north, Kinmen's vicinity to the People's Republic of China-controlled mainland rendered it strategically important to the government in Taiwan, and Kinmen was substantially militarised and governed under martial law. Kinmen Island's own development accelerated, and its land value increased after demilitarisation in 1992, the creation of tourism development policies, and the implementation of the Mini-Three-Links policy (which lifted trade, postal, and transport restrictions between Kinmen and Matsu and cities in mainland China's Fujian Province) in 2001 (Chen, 2010; Lin \& Chou, 2015).

Long-term military restrictions and inconvenient transportation limited Lieyu's development and has resulted in a unique natural and battlefield landscape. In 2011, construction finally began on the long-discussed Kinmen Bridge (Figure 2) between Lieyu and Kinmen Island. In order to achieve the right balance between development and tourism openness for the islands of Lieyu Township (Dadan, Erdan, and Lieyu itself), the country magistrate promoted a Lieyu Border Island tourism regeneration plan: a construction fund of NT $\$ 1.04$ billion (29 million euro) is expected to be invested in this project between 2016 and 2020. Lieyu has a total area of just $14.85 \mathrm{~km}^{2}$, meaning that approximately NT\$70 million (2 million euro) of construction funds per $\mathrm{km}^{2}$ have been acquired, and since 2011, Lieyu has been allocated considerable additional construction funding (Hong, 2010). These infrastructure and tourism development plans will significantly change Lieyu's landscape. 


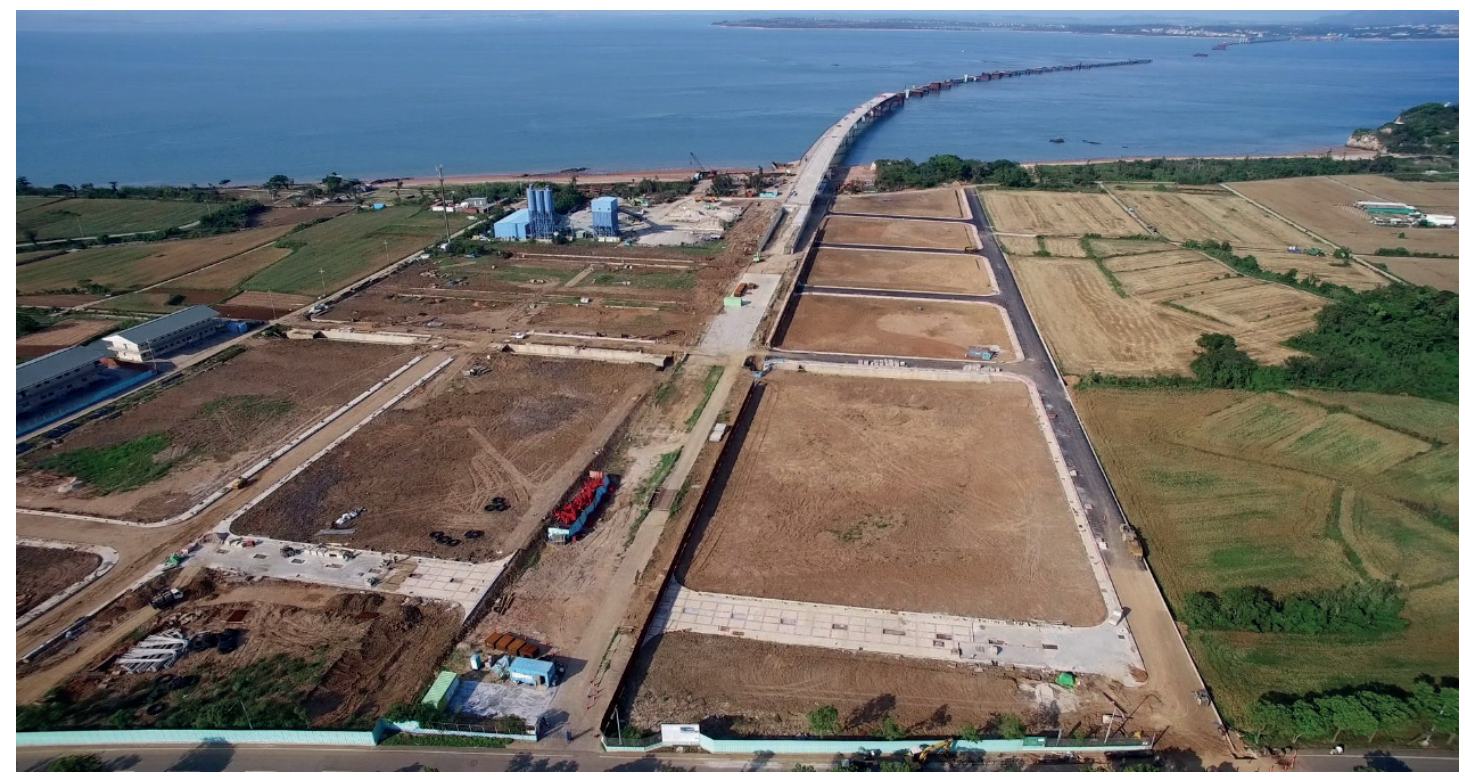

Figure 2: Kinmen Bridge under construction. (C Qing-Zhang Hong, 28 April 2016)

Kinmen Bridge, which will connect Kinmen Island with Lieyu, is currently under construction. The $5.4 \mathrm{~km}$-long bridge, which is expected to be completed in 2018, will have cost nearly NT $\$ 7$ billion (200 million euro) to build. Kinmen Bridge is predicted to significantly influence Lieyu's development, but it is uncertain whether it will negatively affect Lieyu's sense of islandness. As one interviewee says:

Once Kinmen Bridge has been built, what about maritime transportation? I won't deny that the construction of Kinmen Bridge can solve some medical service and traffic issues, but Lieyu will be marginalised. The politicians didn't inform people about the influence big bridges have. They don't foresee the future after 20 years or 50 years [...] We should think about future generations instead of contenting ourselves with current interests. (Interviewee 29)

Transport infrastructure in particular relies on substantial funding (Clark, 2009), and large financial subsidies are a driving force for island development. Ever since the promulgation of the Taiwan Offshore Islands Development Act in 2000, the central government has systematically subsidised an infrastructure fund for outlying islands. Revenue from Kinmen Kaoliang Liquor Inc. (KKL) represents another major source of the income for Kinmen and Lieyu. Interviewee 29 quoted above suggests that "The most pathetic aspect of Kinmen is that it's too rich. The local government is too rich." It has indeed been noted elsewhere that wealthy islands and archipelagos may tend to invest in high-quality infrastructure and development for development's sake, improving some aspects of quality of life while having negative impacts on community sustainability at particular scales within the archipelago as a whole (Grydehøj \& Hayward, 2014; Grydehøj, 2014).

\section{Islander perspectives on Lieyu's archipelagic relationships}

Comparisons and juxtapositions with Lieyu and other islands in its archipelagic system appear frequently in fieldwork interviews concerning Lieyu's development and identity.

For much of the Cold War between mainland China and Taiwan, Kinmen archipelago represented Taiwan's military frontline. Taiwan's central government discouraged civilian infrastructural development until after the islands were demilitarised in the 1990s (Tsai \& Chiang, 2014). A key aspect of this demilitarisation was the establishment of Kinmen National Park in 
1995. Interviewees indicate that most islanders initially supported the creation of a national park on Kinmen Island and Lieyu because this would lead to significant infrastructural investment:

When Kinmen and Lieyu were planned as a national park, the central government claimed to invest NT $\$ 250$ million [7 million euro] in local construction and infrastructure in the beginning. However, the central government was running out of funds. (Interviewee 26)

As time went on, local government (Lieyu Township Office) finances improved, in part through the initial rounds of investment related to the national park and the emergence of other funding sources, such as a gradual increase in KKL's revenues from around 2000. This granted decision-makers on Lieyu greater capacity to undertake development projects. Furthermore, developments on Kinmen Island caused an increase in land prices on Lieyu. In this changed reality, the restrictions on development that accompanied national park status caused Lieyu residents to begin feeling that the national park was restricting their opportunities. In time, the community began requesting that the national park either increase its project subsidies or withdraw from Lieyu.

In my opinion, Lieyu is a 'military' island. The current emotional outbreak of protests against the national park is caused by the former military control and closeness [...] The local government is elected by residents. They treat the national park and armed forces as enemies, which is appealing during election campaigns. The national park actually contributed a lot to Lieyu, especially the preservation of natural and cultural assets. The operations and activities of the national park are actually much better than those of the local government. (Interviewee 21)

Some residents also demand that the military release large amounts of land as part of continuing demilitarisation:

The Department of Defense should return land to the general public and budget for dismantling military camps annually. (Interviewee 5)

Most of the military cultural facilities and camps were dismantled during the return process and returned land to the general public. (Interviewee 2)

In order to please residents, the military subsidises local infrastructure and arranges for soldiers to assist Lieyu Township Office in activities and environmental maintenance (Xu J.K, 2014).

Lieyu receives general subsidisation from Taiwan's Offshore Islands Development Act, Kinmen National Park, and the military. The relationship between Taiwan and Lieyu thus involves a complex relationality, with numerous actors linked to the central government interacting with the local government. Lieyu Township Office argues for subsidies on the basis of the limitations associated with long-term military control, limited land area, and border island attributes.

Lieyu has long seemed peripheral to Taiwan, but it also possesses a peripheral status within the Kinmen archipelago. Lieyu is the only of Kinmen County's five townships that is not located on Kinmen Island, which is nine times larger than Lieyu, has more resources and developable land, and possesses more complete civilian infrastructure (Xu J.T., 2016). All interviewees feel that Lieyu is less developed than Kinmen Island and that this places Lieyu at a disadvantage:

They perceived a sense of deprivation. Why can't they build a farmhouse on their farmland? [...] Kinmen residents tend to feel they're second-class citizens, and those on Lieyu even feel that they're inferior to second-class citizens and are disregarded. They complain a lot because of it. (Interviewee 20) 
Lieyu's certainly behind Kinmen by at least 10 years. It's impossible for the weak to catch up with the strong. (Lieyu Township Leader)

Most islanders know one another, so outsiders are obvious at public hearings and community meetings. Many islanders seek to suppress non-residents' voices and emphasise their village resident identity to exclude other participants from voting on village affairs (Hong, 2013c). This phenomenon of excluding non-residents occurs more often on Lieyu than on Kinmen Island. One interviewee suggests:

We call Kinmen Island 'Houpu' 後浦, while Kinmen people call it 'Kincheng' 金城. Kincheng's cultural background is stronger, while that of Lieyu is weaker. However, affection for Lieyu is stronger. [...] Lieyu's accents are also different from those of Kinmen [...] and some phrases are also different. (Interviewee 27)

Lieyu people worked together, but the other four townships in Kinmen didn't work together. They despised us. Residents of Lieyu are more passionate but are afraid of being caught, reflecting a fear of power. Lieyu is a small place where residents are subject to destiny. (Interviewee 25)

Lieyu residents elect their own township leader, and the township leader and local representatives use their sense of 'island place' (Hay, 2006) to apply for subsidies from the county and central government. Lieyu has not always been as marginal as it is today, in part because its archipelagic relationships were once quite different. Before Taiwan and mainland China were ruled by different regimes, Lieyu residents could take the ferry to Kinmen Island to go shopping but also frequently crossed the bay to procure goods and sell oysters on Xiamen. Lieyu's relationality was formerly oriented toward Xiamen and mainland China in the West rather than toward the Taiwan mainland far to the East. As one interviewee noted:

Those of us from the older generation all went directly to Xiamen Island across the bay by boat. There were many water routes in the past. (Interviewee 36)

Xiamen Island is the urban centre of one of mainland China's Special Economic Zones, and its economy and landscape have developed rapidly since 2000. Interviewees commented on some of these changes:

In the past, we were much better than they were. However, at present, we've fallen behind them a lot. It's really horrible. (Interviewee 15)

In 1993, 1994, there was only one travel agency in Xiamen, and it was run by Taiwanese people. Xiamen's development has sped up over the past decade. (Interviewee 16)

There were no skyscrapers in Xiamen in the past, but now there are a lot. So some people suggest that Kinmen should develop like Xiamen. However, there are a lot of factors they don't take into account, such as transportation and small hinterland. Kinmen can't be developed like Xiamen. (Interviewee 2)

See! Kinmen and Xiamen are both islands. Why is Xiamen getting larger? Xiamen implemented land reclamation projects and created land on the sea. (Interviewee 13)

In recent years, Xiamen's development has stimulated and guided that of Lieyu. The annual Kinmen-Xiamen Swimming Competition offers one example. This activity is located in the 
national park, on Lieyu's Shuangkou Coast, and the area's derelict military infrastructure was removed to help transform the landscape into a recreational zone. Xiamen's skyline and seascape have, moreover, become a tourism resource for Leiyu, from which visitors can get a fantastic view (Figure 3). Comparisons with Xiamen's rapid development across the bay have strengthened some islanders' attitudes regarding their own island's development. The County Government Magistrate and planners emphasise the sharp developmental contrast between Xiamen and Lieyu to convince policy reviewers of the importance of enabling Lieyu to catch up with Xiamen. This helps justify infrastructure subsidies for Lieyu as well as guides Lieyu's tourism development and construction plans.

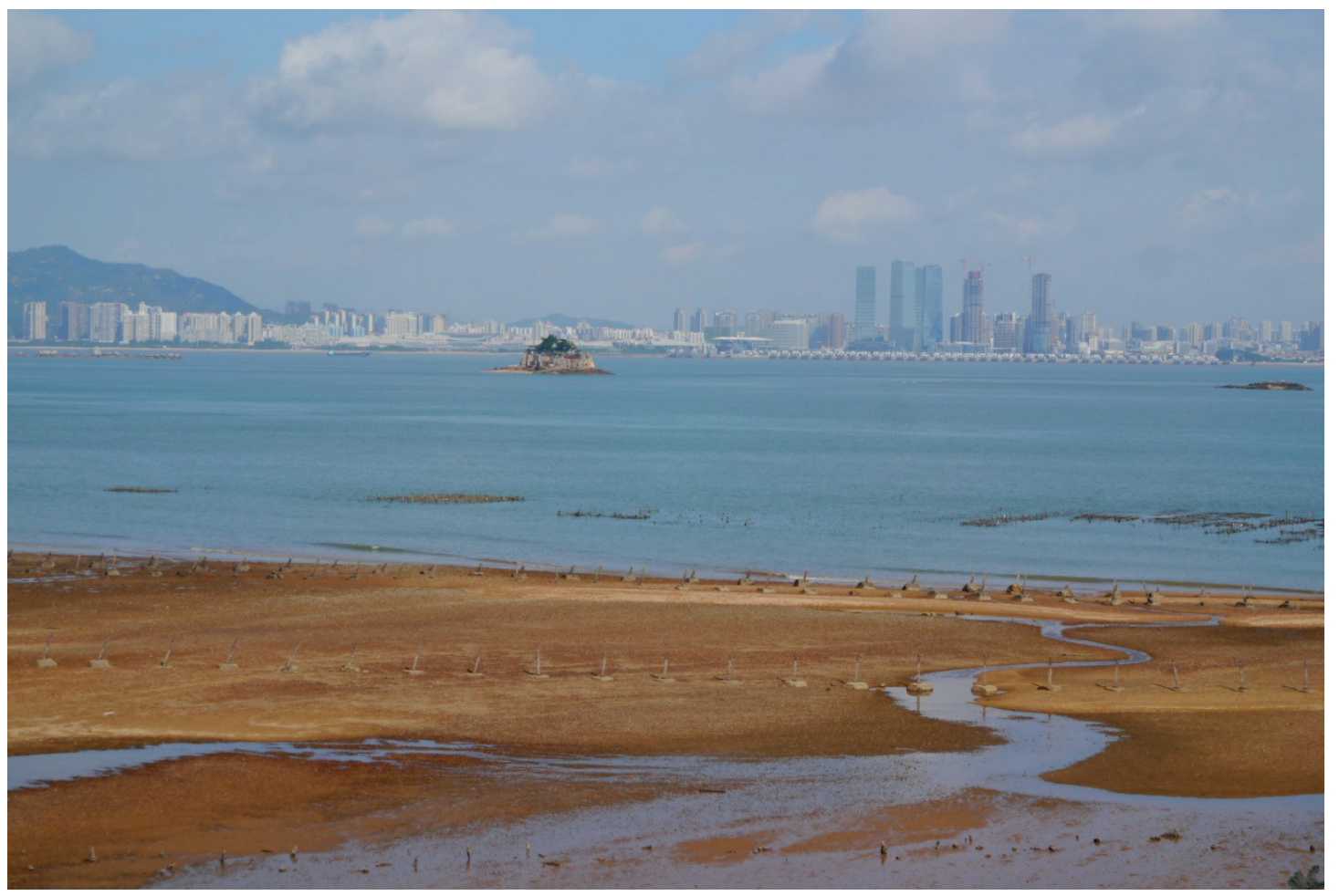

Figure 3: The urban seascape of Xiamen, from Lieyu's coast. (C) Wen-Hua Huang, 13 July 2014)

\section{Development policy, employment, and loss of island values}

The main development actors on Lieyu are the Lieyu Township Leader, local elected representatives, village leaders, and township consultants, followed by the county magistrate, community committees, and clan representatives.

Interviewees state that the Township Office creates many job opportunities and improves residents' welfare. The Township Office aggressively applies for infrastructure funds from the central and county governments $(\mathrm{Xu}, 2014 \mathrm{a})$, and many young adults are engaged in the construction industry. The Township Leader and elected representatives frequently use the creation of job opportunities as a rationale for applying for infrastructure subsidies. This leads to the construction of infrastructure for its own sake, a process that can have negative impacts and prove difficult to break free from (Grydehøj, 2014). Lieyu residents regard job opportunities as the most important factor in place dependence, that is, an "individual's perception of being strongly attached to" a place (Stokols \& Shumaker, 1982, pp. 157-158).

There is a deficiency in Lieyu: the lack of job opportunities. If residents can have a stable job, most will stay here. [...] In the past, most young people studied at universities elsewhere. Now there's National Quemoy University, so more young people are returning. Job opportunities were the key factor affecting students' willingness to return to work. (Interviewee 1) 
There are no good job opportunities for young people here, which is a disadvantage. Young people have to seek jobs in Taiwan and elsewhere. (Interviewee 3)

In the past, there were no jobs for young adults in Kinmen because young adults sought jobs elsewhere. At present, as long as you can find a job here, you can make a living here. (Interviewee 15)

Only those who could find jobs here would live here. (Interviewee 38)

Such place dependence primarily represents attachment to livelihood (Proshansky et al., 1983; Stokols \& Shumaker, 1981). The Township Leader has applied for large infrastructure subsidies, which mainly create job opportunities for fixed-term contract employees in the construction industry and public sector, necessitating a constant flow of construction projects. Lieyu residents are supportive of these actions, and the Township Leader won consecutive elections before standing for election uncontested.

Most Lieyu islanders are supportive of public infrastructure and tourism development. Our fieldwork suggests three important factors behind this support:

1) Islanders agree that island infrastructure and development are good in general;

2) Due to territorial differences, residents of one village do not comment upon residents of other villages;

3) Most islanders are unwilling to express opinions concerning cross-territorial or whole-island major infrastructure projects due to their close relationships with other islanders.

As a result, few islanders oppose large-scale infrastructure and development. We have, however, found some residents who question the necessity of construction and infrastructural development on Lieyu and argue that projects should be more thoroughly evaluated and assessed:

Some of the infrastructure projects were planned according to the opinions of a few residents, and they're populist construction, which ruins Lieyu's environment. (Interviewee 2)

We certainly have to limit development, preserve local characteristics, and construct infrastructure. The Township Leader needs to possess vision and foresight without simply following trends. (Interviewee 25)

These few opponents indicate that it is stressful to stand up against construction on Lieyu because authorities tend to pressure them through interpersonal relationships and with reference to the majority opinion.

Honestly, I disagree with these infrastructure projects. However, in our village, every decision is made according to the opinion of the elders and attitude of the majority. So there's usually little opposition, or opponents usually don't express any opinion. (Interviewee 8)

The changes to Lieyu are mainly made by the Township Leader. Although it's important to complete the infrastructure projects residents want, there are still important aspects to think about [...] Interpersonal relationships are powerful. They can also be a burden. Residents may be afraid of mentioning disadvantages. (Interviewee 25)

There are many underground elites in Kinmen. [...] But they're unwilling to step up and expose themselves in a fight against those who are involved in the gravel construction industry. (Interviewee 20) 
Our villages are natural villages. Some of the villages are formed by kinship, in which everyone is aware of everyone else's background. (Interviewee 25)

Some interviewees use social media to gather different opinions and provide more evidence to amend or terminate some of the infrastructure projects:

Some of the public infrastructure projects actually damage the environment. (Interviewee 2)

The national park coastline has also been gradually taken by the Township Office for construction. (Interviewee 2)

There's nothing wrong with having some changes in one's hometown. However, the hometown should be maintained so wanderers can return home. (Interviewee 29)

In order to appeal for financial subsidies from the Fisheries Agency, Lieyu's Township Leader argued that the border islands are underdeveloped. This process is common in island communities around the world, where political actors engage in a discourse and often quantification of underdevelopment as a means of accessing external funds - even though measures of mainland and island development may not be directly comparable (Grydehøj \& Hayward, 2014).

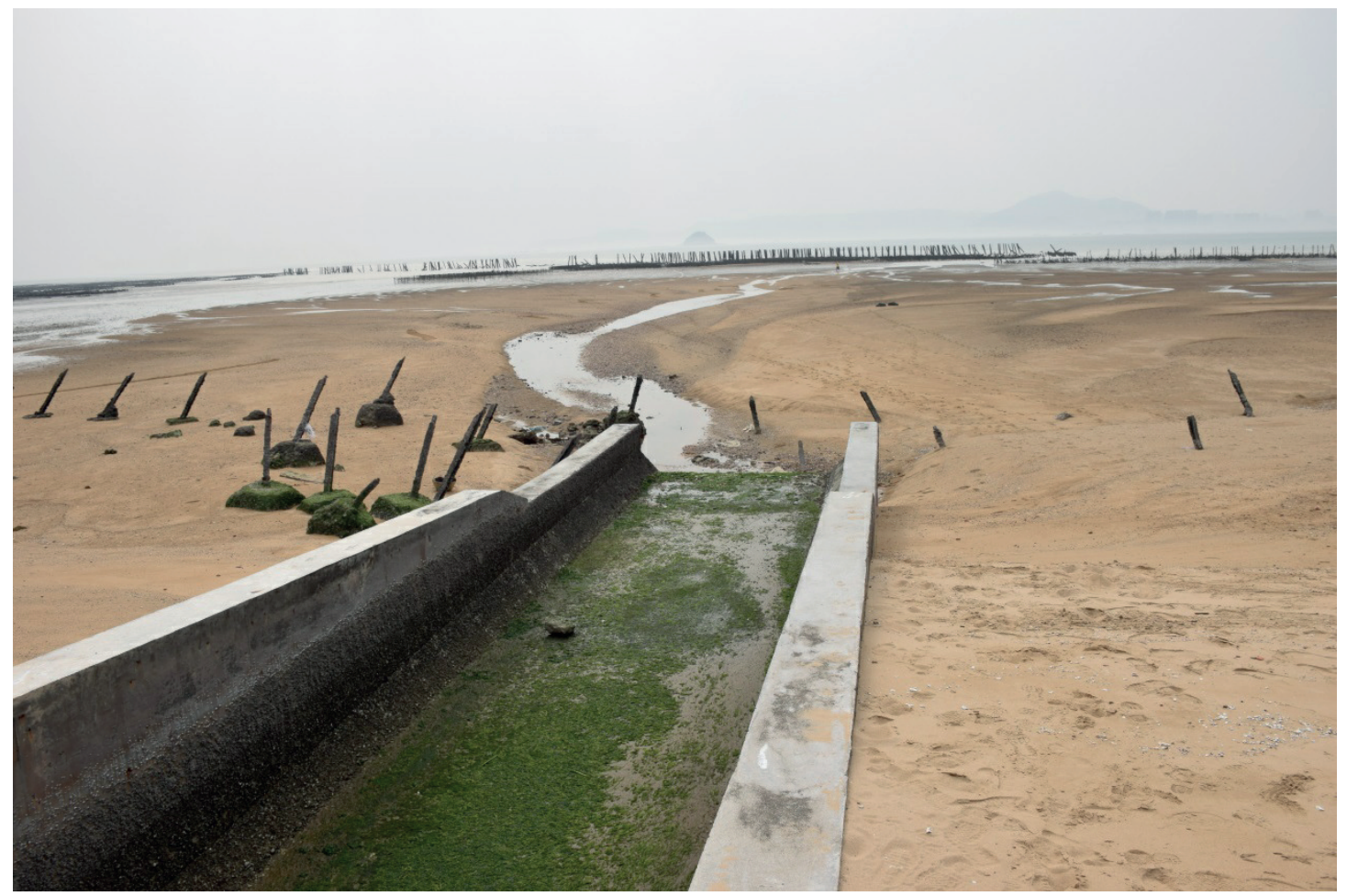

Figure 4: The 'jetty effect' at the Zhongdun Outlet project (Source: (C) Wen-Hua Huang, 3 April 2016)

The construction of Shanglin Oyster Road is an example of the risky nature of poorly planned infrastructure development. This road was constructed across sandy beaches and mudflats using concrete modules. The road is located at the intertidal zone, is used by oyster farmers, and can only be walked on at low tide. Although this road was constructed by the Township Office in response to the desires of Shanglin oyster farmers, not everyone in Shanglin and the other villages approved of the project. Within two months of completion of construction, the "jetty 
effect' had occurred, as "hard coastal structures [...] placed on sedimentary coastlines [cause[ erosion of the down-drift shoreline" (Liu \& Lin, 2011). This has led to gravel and moss covering the Shanglin Oyster Road. Interviewees indicate that several residents have slipped and gotten hurt when riding motorbikes on the road. The 'jetty effect' has also caused erosion and beach damage at the site of the Zhongdun outlet project (Figure 4). Because environmental impact assessments are not required for such small-scale construction, the Township Office underestimated the impact the road would have on the intertidal zone and coast and vice versa. The planning process did not take into account the island's environmental features, overlooked the diversity of local opinion, and lacked expertise in sensitive coastal and wetland environments.

Opponents of this political-economic process argue that it is important to review construction and engineering quality for Lieyu's numerous infrastructure projects (Hong, 2013a). Our study suggests that some infrastructure projects are necessary for Lieyu's modernisation. However, interviewees state that, in addition to infrastructure that benefits the community as a whole, there are derivative or subsidiary construction and tourism development projects that serve the needs and heed the opinions of very small numbers of residents alone. This is despite the potential for such projects to damage the environment, waste funds, hamper efforts to preserve the island landscape (Hong, 2013a, 2013b), and distort the values of the island community as a whole:

The roads in all the villages have been paved with slate. There are many streetlights in rural villages. Kinmen doesn't have a big population. Do we really need luxurious facilities? What a waste! (Interviewee 26)

Who exactly is using the expanded port? The port scenery is messy. We need careful planning to set Lieyu's medium and long-term visions, which can't be developed arbitrarily. (Interviewee 25)

Many things have been gradually distorted, and values have also changed [...] It's because of money. Today, many people demand compensation and demand their interests. They don't feel they have obligations and won't simply wait for money. (Interviewee 2)

Some researchers argue that when mobility improves and transport becomes convenient, people are deterritorialised and disembedded from place (Appadurai, 1996; Hannerz, 1996). Leung et al. (2017) show how the impetus toward fixed transport links in an archipelago can sweep away legitimate concerns about what kinds of mobility are actually best for island communities. Currently, Lieyu islanders' positive expectations toward Kinmen Bridge outweigh their concerns:

Most residents support construction of the bridge, and only a very few stores and environmentalists are against it. (Interviewee 26)

We've been looking forward to the bridge for decades. Those who are against it are the owners of land near the bridge. (Interviewee 5)

Development projects on Lieyu place the island's existing environmental and social values at risk but have, up to now, maintained support from most islanders.

\section{Archipelagic relationality and compensatory destruction}

Schumpeter (1975) regards 'creative destruction' as the key driver of technological and industrial change in a market economy: new entrepreneurs launch technologies, products, or services that compel pre-existing entrepreneurs to exit the market when their services are rendered obsolete. Harvey (2006) uses 'creative destruction' to conceptualise a modernity that emphasises departure 
from the past. For Harvey, however, such modernity is illusory because it is impossible to fully leave one's past behind. Building upon this concept, we propose the term 'compensatory destruction', which involves destroying existing place-based values or attributes in the process of implementing new values in the name of development.

Kinmen Bridge and the Lieyu Regeneration Tourism Plan (approximately NT\$1.04 billion [29 million euro]) are large-scale examples of compensatory infrastructure construction aiming to improve quality of life and convenience on the island (Xu J.T., 2014b), while projects such as the Zhongdun Outlet and the Shanglin Oyster Road exemplify this on a smaller scale. Such projects destroy or place at risk certain existing, positive attributes of islandness in pursuit of development relative to Taiwan, Kinmen Island, and Xiamen. Although abundant financial subsidisation is a powerful driving force for transforming Lieyu into a 'modern' society, if there is insufficient social and environmental assessment and genuine democratic participation in decision-making, this could destroy the features that make the island worth living on for its existing residents.

Completion of Kinmen Bridge will increase islanders' mobility, yet evidence from elsewhere (Baldacchino, 2007) suggests it will affect the sense of islandness and embeddedness of islanders on Lieyu as well as alter Lieyu's local identity. Development-oriented improvements to mobility and communication often reveal the values of island communities or set dividing lines within such communities (e.g., Baum, 1997; Brophy, 2017; Gillis, 2004; Grydehøj \& Hayward, 2011; Raadik Cottrell, 2017; Stratford, 2008). If nothing else, the combination of island population growth and lessened importance of maritime transport that typically accompanies fixed transport links represents a fundamental change in island life (Leung et al., 2017). Grydehøj and Hayward (2014) find evidence not just that convenient transport can negatively affect peripheral communities within archipelagic networks but also that specifically inconvenient transport can have a protective effect on the smallest of island communities. Dahlman (2009) argues that 'border areas' tend to be sources of a particular form of place identity, which centres upon residents' sense of belonging to a place (Qian et al., 2011). Increased mobility between Kinmen Island and Lieyu will decrease the extent to which Lieyu represents a border zone, thereby potentially affecting islanders' sense of place and challenging their identity. Will the result be the formation of a new peninsular (rather than island) identity (Baldacchino, 2007)? Such identity issues are fundamentally relational (Massey, 1993). Islanders might experience a shift from a conservative and passive identity that is caught in the borderlands to one that is extroverted, active, and politically optimistic (Cresswell, 2013). These identities differ, but it cannot be taken as given that the former is more of an 'island identity' than the latter.

On Lieyu, these processes of compensatory destruction are closely linked to the island's relationality within its wider archipelago (encompassing the Kinmen Archipelago, Taiwan, and Xiamen). Lieyu Township Office engages in relational governance, continually positioning the small island relative to other islands within its archipelago, in order to obtain construction subsidies. As a consequence, local government policies emphasise relative modernisation and development over other island values. In common with the creative destruction theorised by Harvey (2006), compensatory destruction is grounded in a break from the past. The Lieyu Township Office Leader and other local politicians express a desire to overcome economic stagnation and boost growth through financial subsidies for projects that explicitly compensate for Lieyu's geographical (peripheral island) disadvantages and criticise what is regarded as an uneven distribution of resources (an inherently relational assessment). However, because studies are not undertaken into the island's capacity to cope with major changes or into the appropriateness of particular projects and because governance processes remain opaque, these efforts risk causing Lieyu irreversible natural, cultural, and social damage, without necessarily improving the lives of islanders in ways that islanders wish to have them improved. Yet in a world of island relationality, undertaking such studies of islands 'on their own terms' (McCall, 1994) is no easy task since an island's own terms may be inextricably bound up with those of other islands and mainlands (Grydehøj, 2017). 
The relationship between Lieyu and the main island of Taiwan is characterised by the economic and developmental disparity between the two islands, in which the dominant unit subsidises a small, peripheral territory. The Township Office successfully cultivates continual subsidisation from the central government (Xu J.T., 2012) by emphasising the small island's long period of military control, border location, and limited development by mainland standards. The relationship between Lieyu and Kinmen Island is similarly one of uneven development since Lieyu is an island with its own local government within the archipelagic Kinmen County. The relationship between Lieyu and Xiamen is highly complex, given the changing conditions on these two islands over the past decades. Both Lieyu and Kinmen Island are much closer to Xiamen than to the Taiwan mainland, so close indeed that there have been discussions concerning a future bridge linking Kinmen with Xiamen. Tourism to Leiyu by both Taiwanese and Chinese nationals is driven in large part by this proximity. Nevertheless, there remains a substantial political distance between Lieyu and Xiamen, with the result that even though decisions made on Xiamen affect life on Lieyu, and even though Lieyu's relationship with Xiamen plays an important role in the Lieyu Township Office's political rhetoric, these two islands have no direct involvement in one another's formal governance processes.

This also highlights the degree to which archipelagic relationality is changeable. Peripherality is relative and dependent on the networks in which an island is embedded: after all, while Xiamen is a centre of regional power, nearby Lieyu is marginalised and at the periphery of not only Taiwan as a whole but even the Kinmen Archipelago of which it forms a part. In the past, however, before it came under the administration of a government located in distant Taipei, Lieyu was relatively far less peripheral, and was an island just off the coast of the mainland rather than a distant outlying island. Should a bridge ever be constructed to physically connect Lieyu with Xiamen, the islands' relative peripheralities and centralities will shift once again.

Pugh (2016) - gaining inspiration from scholars such as DeLoughrey (2007), Hayward (2012), Hay (2013), and Steinberg and Peters (2015)—stresses the importance of including ships and the sea in our analyses of archipelagic relationships. While this is a necessary reminder for an island studies literature that has at times neglected the ocean, it is also difficult to avoid concluding that, as Lieyu 'develops' and 'modernises', its small-island character is becoming increasingly dependent on fixed transport links and other forms of connective infrastructure, and its archipelagic relationality is losing some its oceanic aspects. The sea can never be removed from an island's history, but as the cases of 'former islands' such as Mumbai, Macau, Tokyo, and (from some perspectives) multiply linked Xiamen demonstrate, it is possible to remove an island from the sea. Archipelagic relationalities are constructed and maintained by people, by islanders themselves. If we aim to improve quality of life for islanders on islands, it is vital that we not confuse what is good for islanders with stasis for its own sake, that we do not remove islanders' agency to define their own archipelagic relationality.

\section{Conclusion}

Lieyu possesses a complex — and to some degree self-constructed-archipelagic relationality, in which the island always seems to be at the bottom of the relative developmental ladder. This has caused Lieyu residents to adopt a sense of geographical disadvantage and underdevelopment as well as a habit of engaging in infrastructural development projects for their own sake. Precisely because Lieyu's politicians have emphasised the island's underdevelopment relative to mainland measures, Lieyu has gained access to considerable external financial resources and infrastructure funding. Lieyu residents generally feel that the positive effects of connective infrastructure outweigh their negative social, cultural, and environmental effects. In the past, residents of Kinmen Island and Lieyu were broadly favourable about the creation of Kinmen National Park, which has come to cover a large area. However, as local government finances improved and opportunities for development increased, public support for the national park decreased. The relationships 
between Lieyu's local government and the governments of Kinmen and Taiwan have thus evolved over time, alternating between perceptions of local developmental obstruction and promotion. We use the term 'compensatory destruction' to describe many of the infrastructural development projects on Lieyu: such projects may have profound negative environmental, cultural, and social impacts, but policymakers and many residents regard the loss of existing local island values as a price worth paying for further development, modernisation, and improved quality of life.

'Quality of life' in an abstract sense is not always the same as 'quality of island life'. Experiences from around the world suggest that many islanders decide that larger islands or the mainland offer a higher quality of life than does 'their' small island. By the same token, connective infrastructure that brings a small island closer to a large island or the mainland may be locally regarded as improving quality of life at the same time as it lessens the distinctiveness of small island life. Ultimately, researchers and policymakers must determine how best to balance or whether to privilege a single side in the sometimes-competing desires to improve islanders' welfare and to secure the sustainability of a small island community.

This highlights the need for continuous and relationally sensitive observation of Lieyu's development, especially in terms of the eventual effects of the bridge with Kinmen Island. If infrastructure funds and projects exceed Lieyu's environmental and social capacity and if there is a lack of assessment, the negative influences of these projects risk outweighing the positive results, when the interests of all islanders are considered.

\section{Acknowledgments}

The authors would like to thank Ministry of Science and Technology, R.O.C. for finical support. The Grant No. is MOST 104-2621-M-003-002.

\section{References}

Appadurai, A. (1996). Modernity at large: cultural dimensions of globalization. Minneapolis: University of Minnesota Press.

Baldacchino, G. (2007). Fixed links and the engagement of islandness: reviewing the impact of the Confederation Bridge. Canadian Geographer, 51(3), 323-336. https://doi.org/10.1111/j.1541-0064.2007.00181.x

Baldacchino, G., \& Tsai, H.M. (2014). Contested enclave meta-geographies: the offshore islands of Taiwan. Political Geography, 40, 13-24. https://doi.org/10.1016/j.polgeo.2014.02.002

Baum, T. G. (1997). The fascination of islands: a tourist perspective. In D. Lockhart \& D. Drakakis-Smith (Eds.) Island tourism: problems and perspectives. London: Mansell.

Beller, W., D’Ayala, P., \& Hein, P. (1990). Sustainable development and environmental management of small islands. Paris: UNESCO.

Brophy, J.E. (2017). Reiterating the boundary: community discourse in light of proposed technological change on Vinalhaven Island, Maine, USA. Island Studies Journal, 12(1), 187-206. https://doi.org/10.24043/isj.12

Chen, C.M. (2010). Role of tourism in connecting Taiwan and China: assessing tourists' perceptions of the Kinmen-Xiamen links. Tourism Management, 31(3), 421-424. https://doi.org/10.1016/j.tourman.2009.04.010

Clark, E. (2013). Financialization, sustainability and the right to the island: a critique of acronym models of island development. Journal of Marine and Island Cultures, 2(2), 128-136. https://doi.org/10.1016/j.imic.2013.10.001

Clark, E. (2009). Island development. In R. Kitchin \& N. Thrift (Eds.) International Encyclopedia of Human Geography, 5 (pp. 607-610). Oxford: Elsevier. https://doi.org/10.1016/B978008044910-4.00849-X

Cresswell, T. (2013). Geographic thought: a critical introduction. Chichester: Wiley-Blackwell. 
Dahlman, C.T. (2009). Regionalism. In C. Gallaher, C.T. Dahlman, M. Gilmartin, A. Mountz, \& P. Shirlow (Eds.) Key concepts in political geography (pp. 210-222). London \& Los Angeles: Sage. https://doi.org/10.4135/9781446279496.n23

DeLoughrey, E. (2007). Routes and roots: navigating Caribbean and Pacific island literatures. Honolulu: University of Hawai'i Press.

Figueroa, E., \& Rotarou, E. (2016). Tourism as the development driver of Easter Island: the key role of resident perceptions. Island Studies Journal, 11(1), 245-264.

Gillis, J. (2004). Islands of the mind: how the human imagination created the Atlantic world. Houndmills: Palgrave Macmillan.

Grydehøj, A. (2017). A future of island studies. Island Studies Journal, 12(1), 3-16. https://doi.org/10.24043/isj.1

Grydehøj, A. (2015). Island city formation and urban island studies. Area, 47(4), 429-435. https://doi.org/10.1111/area.12207

Grydehøj, A. (2014). Constructing a centre on the periphery: urbanization and urban design in the island city of Nuuk, Greenland. Island Studies Journal, 9(2), 205-222.

Grydehøj, A., \& Hayward, P. (2014). Social and economic effects of spatial distribution in island communities: comparing the Isles of Scilly and Isle of Wight, UK. Journal of Marine and Island Cultures, 3(1), 9-19. https://doi.org/10.1016/j.imic.2014.03.002

Grydehøj, A., \& Hayward, P. (2011). Autonomy initiatives and quintessential Englishness on the Isle of Wight. Island Studies Journal, 6(2), 179-202.

Hannerz, U. (1996). Transnational connections: culture people places. Routledge: London.

Harvey, D. (2006). Paris, capital of modernity. New York: Routledge.

Hay, P. (2013). What the sea portends: a reconsideration of contested island tropes. Island Studies Journal, 8(2), 209-232.

Hay, P. (2006). A phenomenology of islands. Island Studies Journal, 1(1), 19-42.

Haynes, J. (2008). Development studies. Malden, MA: Polity.

Hayward, P. (2012). Aquapelagos and aquapelagic assemblages. Shima, 6(1), 1-11.

Hong, Q.Z. (2013a). Seminar on Shanglin maritime outfall road reconstruction engineering. Blog of Lieyu Observational Notes, 27 April. http://taconet.pixnet.net/blog/post/39012649

Hong, Q.Z. (2013b). Landmine Theme Park Enrichment Plan. Blog of Lieyu Observational Notes, 27 October. http://taconet.pixnet.net/blog/post/41585421

Hong, Q.Z. (2013c). Observation on scenic and recreational facility construction engineering in Lieyu Township. Blog of Lieyu Observational Notes, 29 October. http://taconet.pixnet.net/blog/post/41597497

Hong, Q.Z. (2010). In the past five years, what did Kinmen National Park do on Lieyu? Blog of Lieyu Observational Notes, 4 May. http://taconet.pixnet.net/blog/post/30515681

Leung, A., Tanko, M., Burke, M., \& Shui, C.S. (2017). Bridges, tunnels, and ferries: connectivity, transport, and the future of Hong Kong's outlying islands. Island Studies Journal, 12(2). https://doi.org/10.24043/isj.24

Lin, C.S., \& Chou, H.Y. (2015). Dimensions and effects of consumers' travel-transportation involvement: the case of the Mini Three Links. Asia Pacific Journal of Tourism Research, 20(1), 51-75. https://doi.org/10.1080/10941665.2013.866584

Lin, L.J., \& Liu, Y.C. (2011). Shorelines receding due to jetty effect: academics. Taipei Times, 5 June. http://www.taipeitimes.com/News/taiwan/archives/2011/07/05/2003507463

Luo, B., \& Grydehøj, A. (2017). Sacred islands and island symbolism in ancient and imperial China: an exercise in decolonial island studies. Island Studies Journal, 12(2). https://doi.org/10.24043/isj.19

Massey, D. (1993). Power-geometry and progressive sense of place. In J. Bird, B. Curtis, T. Putnam, G. Robertson, \& L. Tickner (Eds.) Mapping the futures: local cultures, global change (pp. 59-69). London \& New York: Routledge. 
McCall, G. (1994). Nissology: a proposal for consideration. Journal of the Pacific Society, 63-64(17), 99-106.

Nederveen Pieterse, J. (2010) Development theory: deconstructions/reconstructions. London: Sage. https://doi.org/10.4135/9781446279083

Proshansky, H.M., Fabian, A.K., \& Kaminoff, R. (1983). Place identity: physical world socialization of the self. Journal of Environmental Psychology, 3, 57-83. https://doi.org/10.1016/S0272-4944(83)80021-8

Pugh, J. (2016). The relational turn in island geographies: bringing together island, sea and ship relations and the case of the Landship. Social \& Cultural Geography, 17(8), 1040-1059. https://doi.org/10.1080/14649365.2016.1147064

Pugh, J. (2013). Island movements: thinking with the archipelago. Island Studies Journal, 8(1), 9-24.

Qian, J., Zhu., H., \& Liu, Y. (2011). Investigating urban migrants' sense of place through a multi-scalar perspective. Journal of Environmental Psychology, 31, 170-183. https://doi.org/10.1016/j.jenvp.2011.01.002

Raadik Cottrell, J. (2017). Island community: identity formulation via acceptance through the environment in Saaremaa, Estonia. Island Studies Journal, 12(1), 169-186. https://doi.org/10.24043/isj.11

Rankin, J.R. (2016). Tracing archipelagic connections through mainland islands. New Zealand Geographer, 72, 205-215. https://doi.org/10.1111/nzg.12138

Royle, S.A. (2001). A geography of islands: small island insularity. London: Routledge. https://doi.org/10.4324/9780203227404

Schumpeter, J. (1975 [1942]). From capitalism, socialism and democracy. New York: Harper.

Selwyn, R. (2011 [1975]). Development policy in small countries. London: Routledge.

Sheng, N., Tang, U.W., \& Grydehøj, A. (2017). Urban morphology and urban fragmentation in Macau, China: island city development in the Pearl River Delta megacity region. Island Studies Journal, 12(2). https://doi.org/10.24043/isj.25

Stokols, D., \& Shumaker, S.A. (1982). The psychological context of residential mobility and well-being. Journal of Social Issues, 38(3), 149-171 https://doi.org/10.1111/j.1540_ 4560.1982.tb01776.x

Stokols, D., \& Shumaker, S.A. (1981). People in places: a transactional view of settings. In J.H. Harvey (Ed.) Cognition, social behavior, and the environment (pp. 441-488). Hillsdale, NJ: Lawrence Erlbaum.

Steinberg, P., \& Peters, K. (2015). Wet ontologies, fluid spaces: giving depth to volume through oceanic thinking. Environment and Planning D: Society and Space, 33(2), 247-264. https://doi.org/10.1068/d14148p

Steyn, G. (2015). The impacts of islandness on the urbanism and architecture of Mombasa. Urban Island Studies, 1, 55-80. https://doi.org/10.20958/uis.2015.4

Stratford, E. (2008). Islandness and struggles over development: a Tasmanian case study. Political Geography, 27, 160-175. https://doi.org/10.1016/j.polgeo.2007.07.007

Stratford, E., Baldacchino, G., McMahon, E., Farbotko, C., \& Harwood, A. (2011). Envisioning the archipelago. Island Studies Journal, 6(2), 113-130.

Tsai, H.M. (2003). Island biocultural assemblages: the case of Kinmen Island. Geografiska Annaler B, 85, 209-218. https://doi.org/10.1111/j.0435-3684.2003.00143.x

Tsai, H.M., \& Chiang, B.W. (2014). Enclosing resources on the islands of Kinmen and Xiamen: from war blockade to financializing natural heritage. Journal of Marine and Island Cultures, 3(2), 69-77. https://doi.org/10.1016/j.imic.2014.12.002

Vannini, P., \& Taggart, J. (2012). Doing islandness: a nonrepresentational approach to an island's sense of place. Cultural Geographies, 20(2), 225-242. https://doi.org/10.1177/1474474011428098

Willis, K. (2011). Theories and practices of development. London: Routledge. 
Willis, K., \& Kumar, M.S. (2009). Development I. In R. Kitchin \& N. Thrift (Eds.) International encyclopedia of human geography, 3 (pp. 111-116). Oxford: Elsevier. https://doi.org/10.1016/B978-008044910-4.00087-0

Xu, J.K. (2014). Military donation and coordination on Lieyu. Kinmen Daily News, 11 July. http://www.kmdn.gov.tw/

$\mathrm{Xu}$, J.T. (2016). The Township Governor listened to suggestions from the islanders who moved to Taiwan at the forum. Kinmen Daily News, 4 January. http://www.kmdn.gov.tw/

$\mathrm{Xu}$, J.T. (2015). The discussion of Lieyu's consultancy forum is very enthusiastic. Kinmen Daily News, 15 December. http://www.kmdn.gov.tw/

Xu, J.T. (2014a). The Township Governor has made a policy address at regular meetings of parliament. Kinmen Daily News, 25 November. http://www.kmdn.gov.tw/

Xu, J.T. (2014b). The Township Governor confirmed the construction of the township at the regular meeting. Kinmen Daily News, 15 October. http://www.kmdn.gov.tw/

Xu, J.T. (2012). The Township Governor has a policy address. Kinmen Daily News, 21 November. http://www.kmdn.gov.tw/

Yang, S.Y. (2016). The magistrate talks about a vision of construction on Lieyu. Kinmen Daily News, 23 January. http://www.kmdn.gov.tw/ 